\begin{tabular}{|c|c|c|}
\hline $\begin{array}{c}\text { The Assessment of the Mesozooplankton } \\
\text { Community from the Romanian Black Sea } \\
\text { Waters and the Relationship to } \\
\text { Environmental Factors }\end{array}$ & $\begin{array}{c}\text { "Cercetări Marine" } \\
\text { Issue no. 51 }\end{array}$ & \\
$\begin{array}{c}\text { (Elena Bișinicu, Valeria Abaza, Victor Cristea, } \\
\text { George Emanuel Harcotă, Luminița Lazăr, } \\
\text { Cristina Tabarcea, Florin Timofte) }\end{array}$ & Pages 108-128 & $\mathbf{2 0 2 1}$ \\
\hline \multicolumn{2}{|c|}{ DOI:10.55268/CM.2021.51.108 } \\
\hline
\end{tabular}

\title{
THE ASSESSMENT OF THE MESOZOOPLANKTON COMMUNITY FROM THE ROMANIAN BLACK SEA WATERS AND THE RELATIONSHIP TO ENVIRONMENTAL FACTORS
}

\author{
Elena Bișinicu' ${ }^{1}$, Valeria Abaza1, Victor Cristea², \\ George Emanuel Harcotă ${ }^{1}$, Luminița Lazar ${ }^{1}$, \\ Cristina Tabarcea ${ }^{1}$, Florin Timofte ${ }^{1}$
}

${ }^{1}$ National Institute for Marine Research and Development "Grigore Antipa”, 300 Mamaia Blvd., 900581, Constanta, Romania

${ }^{2}$ Dunărea de Jos " University of Galati, Cross-Border Faculty of Humanities, Economics and Engineering, 47, Domneasca Str., 800008, Galati, Romania E-mail: ebisinicu@alpha.rmri.ro

\begin{abstract}
The paper aims to develop and test a semi-quantitative method that generates scenarios for the zooplankton community development under salinity and nutrients fluctuations. First, we identified the relationships between the mesozooplankton component and the environmental factors by analyzing data $(\mathrm{N}=2566)$ collected within the warm season (May-September) of a decade (2008-2018). The biotic and abiotic parameters were investigated at 37 stations within the monitoring network of the Romanian Black Sea waters, covering all three marine reporting units (waters with variable salinity, coastal and marine) according to Marine Strategy Framework Directive (MSFD). We identified 32 mesozooplankton species belonging to ten taxonomic classes, copepods representing the bulk of the community. In waters with variable salinity and coastal waters, the fodder component of the mesozooplanktonic community was dominant, while in marine waters the nonfodder component was better and exclusively represented by Noctiluca scintillans. Physicochemical parameters that showed significant correlations with the mesozooplankton species were $\mathrm{S}$ (salinity) and nutrients - $\mathrm{NO}_{2}^{-}$(nitrite), $\mathrm{NO}_{3}{ }^{-}$(nitrate), $\mathrm{PO}_{4}{ }^{3-}$ (phosphate) and $\mathrm{NH}_{4}^{+}$(ammonium). The number of species significantly correlated with the physicochemical parameters showed variations generally correlated with the increasing salinity gradient: in waters with variable salinity nine species being correlated, in coastal waters ten species, and in marine waters five species.
\end{abstract}

Key-Words: mesozooplankton, fodder, nonfodder, correlations, physicochemical 


\section{AIMS AND BACKGROUND}

The zooplankton community is represented by the assemblage of animals that drift the waters of the world's oceans and seas. These microscopic organisms play a key role in the pelagic food web by controlling phytoplankton production and shaping pelagic ecosystems. In addition, because of their critical role as a food source for larval and juvenile fish, the dynamics of zooplankton populations, their reproductive cycles, growth, reproduction, and survival rates are all important factors influencing recruitment to fish stocks (Harris et al., 2000).

Zooplankton communities respond to changes that occur in the environment, disturbances such as eutrophication, causing rapid changes in populations. Therefore, zooplankton is a potential indicator of water pollution (Ismail et al., 2016). Any variation in zooplankton biomass has implications for fishing and ecosystem services (Caroppo et al., 2013). Thus, because eutrophication causes changes in the qualitative and quantitative structure of zooplankton, its use as an indicator of changes that may occur at the trophic level and ecological conditions caused by nutrient dynamics has a very important role (Jurczak et al., 2019). Accordingly, in the national MSFD assessment (Descriptor 5 - Eutrophication), Noctiluca scintillans is used as the harmful algal bloom indicator (Boicenco et al., 2018).

The paper aims to develop and test a semi-quantitative method that generates scenarios for the zooplankton community development under salinity and nutrients fluctuations. The model was based on qualitative and quantitative structure of the mesozooplankton community and on finding the relationships between mesozooplankton and physicochemical parameters.

\section{EXPERIMENTAL}

We used data from NIMRD expeditions, in the warm season of 20082018, to identify the relationships between the mesozooplankton component and the environmental factors. The year 2012 was not included in the analysis, because no expeditions were carried out in the warm season, but only in the cold season. Data were for collection depths of up to 10m (2-0 m, 5-0 m, 10$0 \mathrm{~m})$.

Zooplankton samples were collected according to the methodology detailed in the Black Sea monitoring manual (Alexandrov et al., 2014), by vertical tows, using a Juday net $\left(0.1 \mathrm{~m}^{2}\right.$ mouth opening area, $150 \mu \mathrm{m}$ mesh size) equipped with a flow meter for estimating the volume of water filtered.

The quantitative and qualitative processing of the mesozooplankton samples was performed in the Bogorov chamber, under Olympus SZX10. In the subsample(s) all plankters were counted until each of the three dominant taxonomic groups reached 100 individuals. For estimation of large animals 'numbers, the whole sample was examined in a Petri dish. The number of 
individuals and mean individual weights were used for estimating the density as ind. $\mathrm{m}^{-3}$, respectively the biomass as $\mathrm{mg} \cdot \mathrm{m}^{-3}$ wet weight (Alexandrov et al., 2014).

Temperature and salinity were measured simultaneously with plankton sampling using the reversible thermometer and the CastAway CTD multiparameter. Several salinity samples and all nutrients' samples were analyzed in the NIMRD's laboratory, according to the standard methods for seawater analysis (Grasshoff et al., 1999).

Samples were collected from 37 stations within the marine environment monitoring network on the Romanian Black Sea coast, of which, 9 stations in waters with variable salinity, 14 stations in coastal waters and 14 stations in marine waters (Fig. 1).

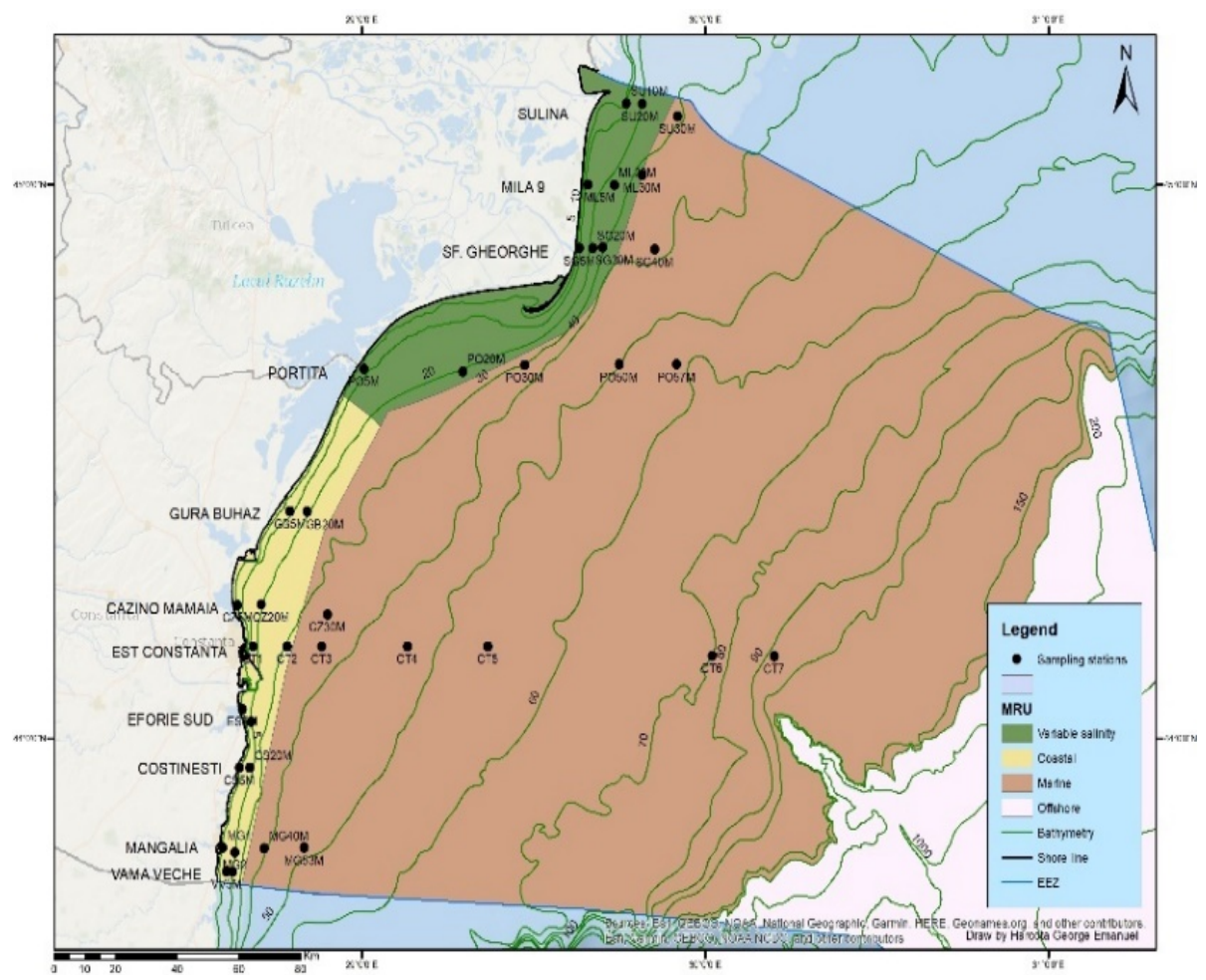

Fig. 1. Map of sampling stations - Romanian Black Sea, 2008-2018

For data analysis, we used specific software as follows: XLSTAT for data analysis, Primer for statistical analysis, ArcGis for maps, Mental Modeler software (http://www.mentalmodeler.org/) for cognitive maps (FCM - fuzzy cognitive maps), models and scenarios. PRIMER was used for Non-metric Multidimensional Scaling (n-MDS) and SIMPER configuration. SIMPER examines the relationships between species and sample patterns, with variables that are likely to contribute to any differences between groups being 
identified; n-MDS is a mean of visualizing the similarity level of a data set (Clarke et al., 2014).

FCM is a complex form of data analysis that results in qualitative static models that are translated into quantitative dynamic models. FCM represents knowledge by defining three characteristics of a system: the components of the system (mesozooplankton species and abiotic parameters), the positive or negative relationships between the components and the degree of influence that one component can have on another, defined using qualitative weightings (e.g. high, medium, or low influence $)^{1}$. We used as qualitative weighting the significant Pearson correlation coefficients.

Once an FCM is developed, it can be used to test "what if" model scenarios, allowing users to assess system dynamics by artificially increasing or decreasing model components. Mental Modeler provides users with a way to develop a simple qualitative FCM, which is then translated into the quantitative structure needed to run dynamic FCM scenarios (Gray et al., 2013).

For the model scenarios, we chose to test changes in salinity in variable salinity and marine waters, and phosphate in coastal waters. These choices were made considering the influence of the Danube and other rivers discharging into the NW Black Sea. Additionally, over the past several decades, rising inputs of nitrogen to estuaries and coastal waters throughout the world have outpaced inputs of phosphorus, largely because of singlenutrient management strategies that have focused on phosphorus reductions while nitrogen inputs continue to rise (Bentley et al., 2021).

\section{RESULTS AND DISCUSSION}

We identified 32 mesozooplankton species belonging to ten taxonomic classes (Annex 1). In waters with variable salinity, copepods dominated with 12 species, but the group of Cladocera with ten species also had a high contribution. In coastal waters, the dominance of copepods again with 12 species is noticeable, being followed by Cladocera with five species. The highest value for copepods (13 species) was recorded in marine waters, followed by the meroplanktonic component. The nonfodder component occurred in all three water bodies, the dinoflagellate Noctiluca scintillans being the only representative species. Therefore, the variability between water bodies diversity is due to the halving of the species number in the Cladocera group in the coastal and marine waters (Fig. 2).

High average densities of Noctiluca scintillans are observed on Mila 9, Est Constanța and Costinesti profiles (Fig. 3). From the group of copepods, Acartia clausi reached high average densities in all profiles. Penilia avirostris

\footnotetext{
${ }^{1}$ https://www.mentalmodeler.com/
} 
and Pleopis polyphemoides which belong to Cladocera also recorded high average densities, Penilia avirostris being best represented (Fig. 3.), as an important component of the mesozooplankton of shelf waters during the stratification period (Atienza et al., 2006) adapted to succession under low food conditions and outcompete other components of the marine zooplankton, such as copepods (Atienza et al., 2006). The temporal distribution of Cladocera species is discontinuous, with high abundances from early spring to late autumn, with a rapid decline in winter (Pestoric et al., 2010). Bivalvia and Balanus registered a maximum development in the coastal areas of Eforie, Costinesti, Mangalia. Mesopodopsis slabberi, Oikopleura dioica and Parasagitta setosa were lower represented (Fig. 3).

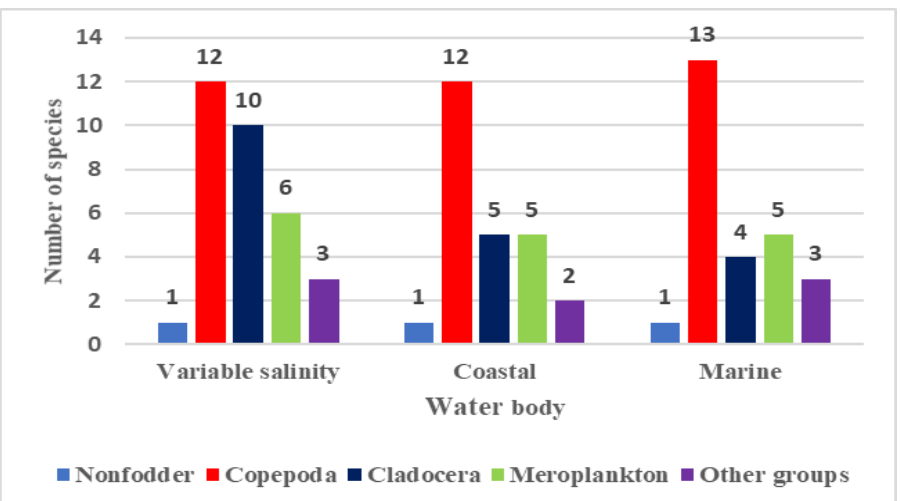

Fig. 2. The qualitative structure of mesozooplankton- Romanian Black Sea, 2008-2018

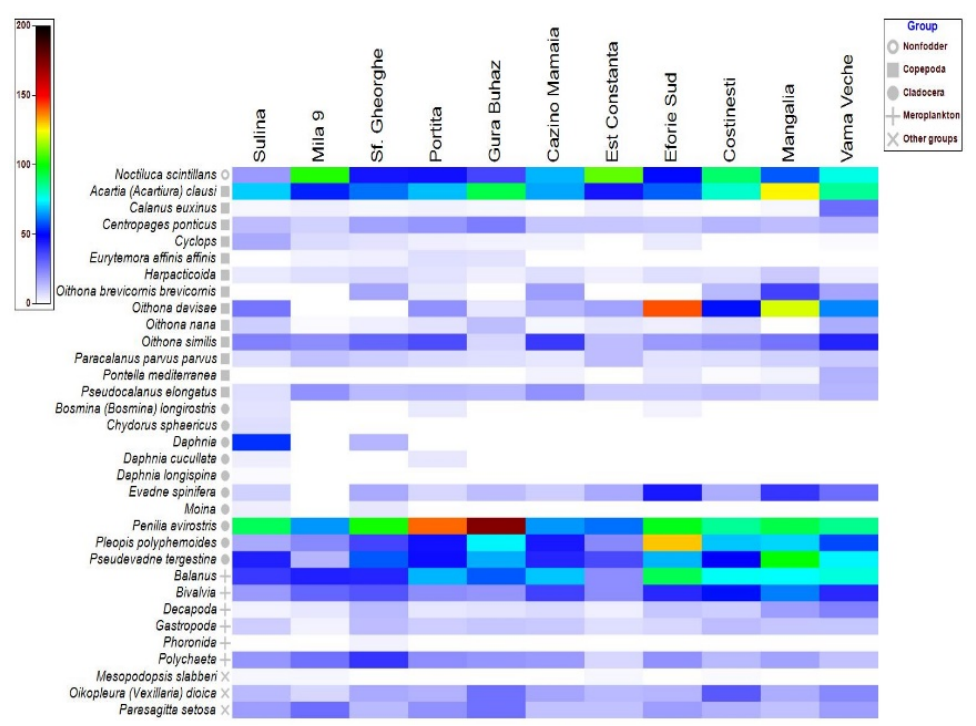

Fig. 3. Shade plot for identified mesozooplankton species (square root transformation) - average densities - Romanian Black Sea, 2008-2018 
Regarding the dominance of the fodder and nonfodder component of the mesozooplankton community, in waters with variable salinity the fodder one was the main contributor (80.93\%), Noctiluca scintillans (nonfodder) registering very low average densities. Fodder mesozooplankton dominated also the coastal waters, with a contribution of $60.41 \%$ of the total average density. On the contrary, marine waters are characterized by the dominance of the nonfodder mesozooplankton (57.31\%) (Table 1).

Table 1. SIMPER - Mesozooplankton's contribution based on densities (ind $/ \mathrm{m}^{-3}$ ) Romanian Black Sea, 2008-2018

\begin{tabular}{|c|r|r|r|r|r|}
\hline \multicolumn{7}{|c|}{ Waters with variable salinity } \\
\hline Category & Av.Abund & Av.Sim & Sim/SD & Contrib\% & Cum.\% \\
\hline Fodder & 81.04 & 56.61 & 3.95 & 80.93 & 80.93 \\
\hline \multicolumn{7}{|c|}{ Coastal waters } \\
\hline Fodder & 89.68 & 42.33 & 3.80 & 60.41 & 60.41 \\
\hline Nonfodder & 62.65 & 27.75 & 3.64 & 39.59 & 100.00 \\
\hline \multicolumn{7}{|c|}{ Marine waters } \\
\hline Nonfodder & 58.94 & 37.18 & 2.14 & 57.31 & 57.31 \\
\hline Fodder & 38.14 & 27.69 & 2.35 & 42.69 & 100.00 \\
\hline
\end{tabular}

The non-metric multidimensional scaling, based on the average density values for the fodder and nonfodder component, indicates similarities of $60 \%$ and $80 \%$ between the analysed stations, the fodder component being dominant in some stations while in others the nonfodder component was more representative (Fig. 4).

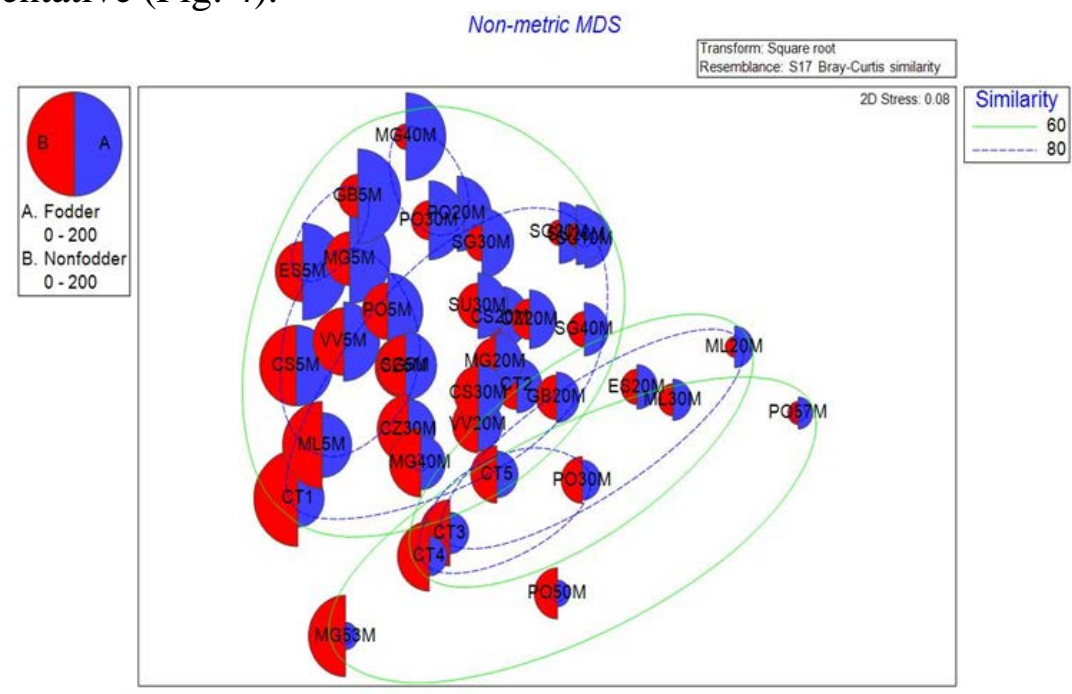

Fig. 4. Non-metric multidimensional scaling (NMDS) ordination based on fodder and nonfodder densities - Romanian Black Sea, 2008-2018 
The biomass of Noctiluca scintillans, reached the highest values in 2010, 2014, 2015 and 2018. The maximum value was recorded in 2010, in CT1 station on Est Constanta profile. There are high similarities between the years, but also between stations, given the biomass recorded by this dinoflagellate (Fig.5).

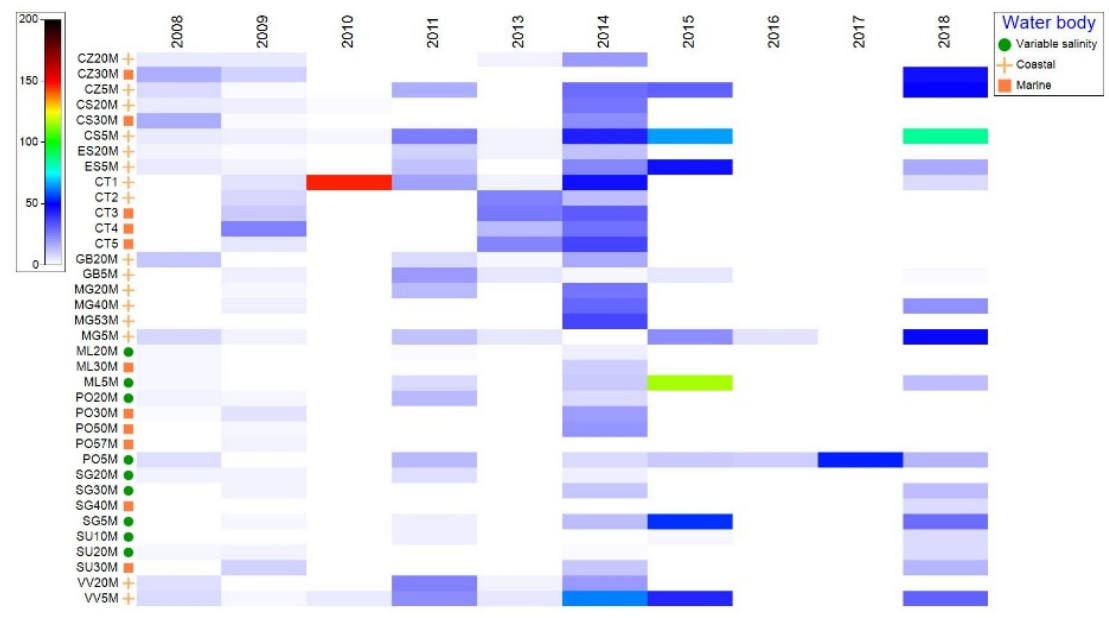

Fig. 5. Shade plot for Noctiluca scintillans biomass (square root transformation)Romanian Black Sea, 2008-2018

The fodder component was represented in coastal and marine waters mainly by Cladocera and Copepoda assemblages. In marine waters, copepods and cladocerans are still the main contributors, to which is added the meroplankton component which had higher average densities compared to the other two water bodies, where lower values were recorded (Table 2).

Table 2. SIMPER -Group contribution based on fodder average densities (ind $/ \mathrm{m}^{-3}$ )Romanian Black Sea, 2008-2018

\begin{tabular}{|c|c|c|c|c|c|}
\hline \multicolumn{6}{|c|}{ Waters with variable salinity } \\
\hline Group & Av.Abund & Av.Sim & Sim/SD & Contrib\% & Cum.\% \\
\hline Cladocera & 64.79 & 28.45 & 2.56 & 40.47 & 40.47 \\
\hline Copepoda & 37.66 & 21.02 & 4.50 & 29.89 & 70.37 \\
\hline \multicolumn{6}{|c|}{ Coastal waters } \\
\hline Cladocera & 66.59 & 28.41 & 3.72 & 39.88 & 39.88 \\
\hline Copepoda & 43.87 & 22.89 & 4.12 & 32.13 & 72.01 \\
\hline \multicolumn{6}{|c|}{ Marine waters } \\
\hline Copepoda & 21.14 & 22.30 & 3.70 & 35.56 & 35.60 \\
\hline Cladocera & 23.03 & 16.11 & 1.40 & 25.68 & 61.24 \\
\hline Meroplankton & 14.07 & 12.66 & 2.37 & 20.19 & 81.43 \\
\hline
\end{tabular}


The non-metric multidimensional scaling for the fodder component based on average density values indicates a similarity of $60 \%$ and $80 \%$ between the analysed stations. An outlier was represented by stations PO50M, MG53M and PO57M, where the copepods reached lower densities. These three stations are part of the marine water body, the average density being lower than in the coastal and variable salinity water bodies (Fig. 6).

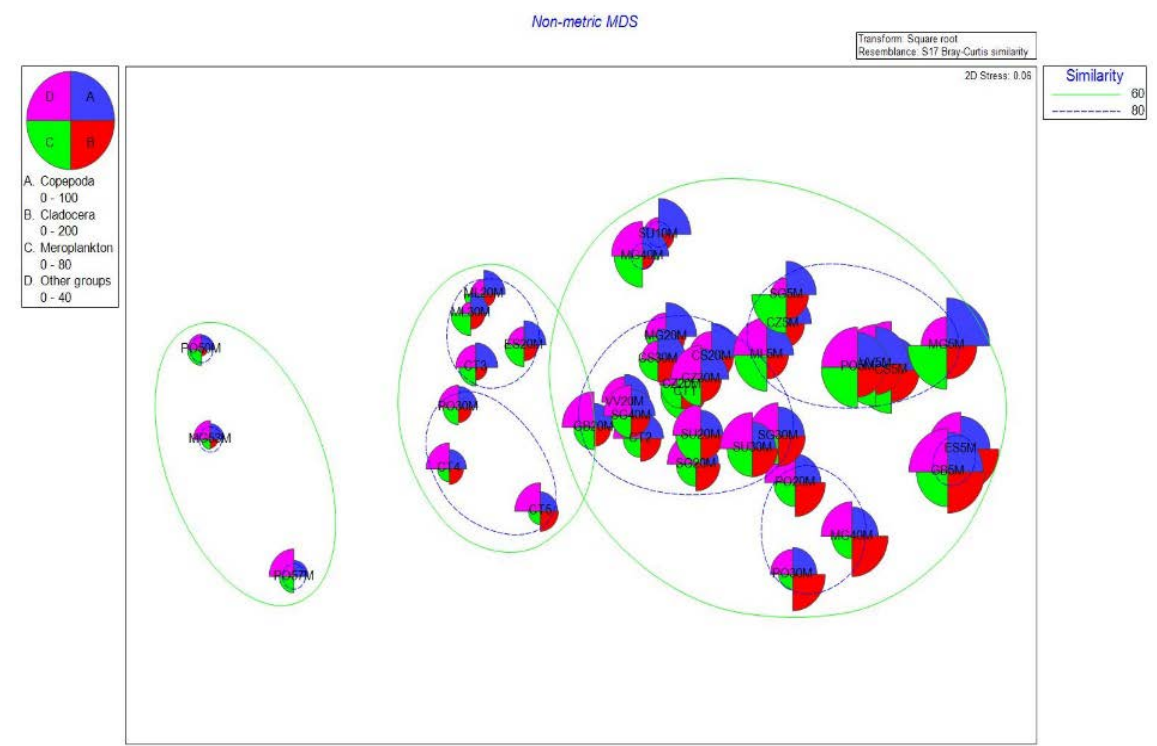

Fig. 6. Non-metric multidimensional scaling (NMDS) ordination based on fodder densities - Romanian Black Sea, 2008-2018 (square root transformation)

Semi-quantitative models of causal relationships between mesozooplankton species and physicochemical parameters were made using the data available in the database $(\mathrm{N}=2566)$ for the warm season, in each water body. To develop the model, the significant $(p<0.05)$ Pearson correlation coefficients between physicochemical parameters and mesozooplankton species grouped according to water body were uploaded to the Mental Modeler software (http://www.mentalmodeler.org/). The positive correlations are represented by blue, and the negative ones by orange. Their weighting represents the coefficient value. According to the principal component analysis (PCA), the physicochemical parameters that showed significant correlations with the mesozooplankton species were $\mathrm{S}$ (salinity), $\mathrm{NO}_{2}^{-}$(nitrite), $\mathrm{NO}_{3}{ }^{-}$(nitrate), $\mathrm{PO}_{4}{ }^{3-}$ (phosphate) and $\mathrm{NH}_{4}{ }^{+}$(ammonium) (Fig. 7).

Physicochemical parameters are important for expertise in the sustainable development process and for management of healthy marine ecosystem (Kennish, 2000). Salinity, and nutrients are used as indicators in the water ecosystem condition (Aknaf et al., 2017). Knowledge of quality water 
and its response to aquatic biodiversity are essential for the management of fisheries, providing a more economic and environmental balanced ecosystem (Romin et al., 2021).

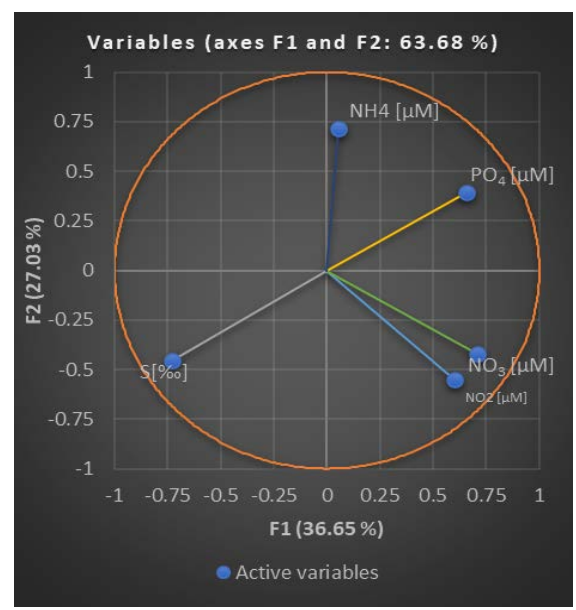

Fig. 7. Principal Component Analysis (PCA) for physicochemical parameters that showed correlation with mesozooplanktonic species Romanian Black Sea, 2008-2018

The number of species significantly correlated with the physicochemical parameters showed variations, in waters with variable salinity nine species showing correlations, in coastal waters ten species, and in marine waters, five species (Fig. 8).

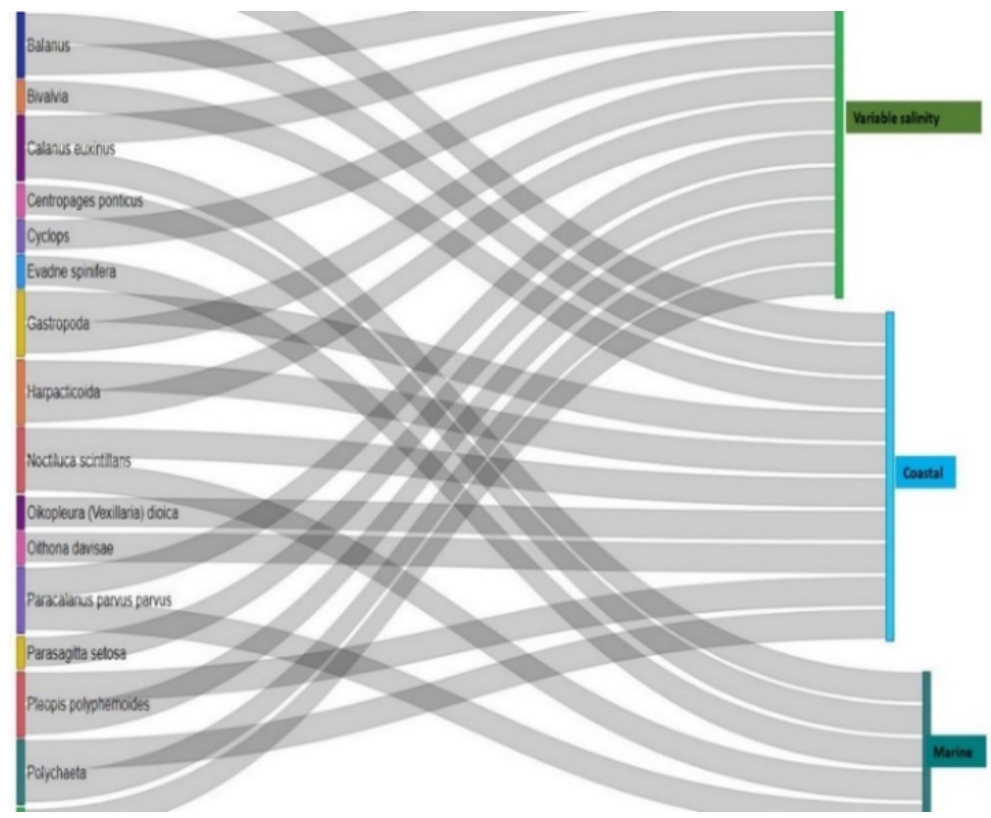

Fig. 8. Mesozooplankton species that showed correlations with physicochemical parameters - Romanian Black Sea, 2008-2018 
In waters with variable salinity, there are positive correlations of the meroplanktonic component represented by Balanus, Polychaeta and Gastropoda with salinity (Fig. 9). Salinity is a key ecological factor in the biology of meroplankton larvae, changes in salinity having a relatively weak influence during the development of meroplankton larvae but generating strong effects on the survival rate (Anger, 2003).

Positive correlations were recorded between the copepod's densities (Harpacticoida, Calanus euxinus, Paracalanus parvus parvus, Pseudocalanus elongatus) and ammonium $\left(\mathrm{NH}_{4}\right)$ (Fig. 9). According to the literature, ammonium is the main nitrogenous product excreted by marine zooplankton. The zooplankton diet can play an important role in determining the type of compounds released by excretion, organic nitrogen excretion increasing when zooplankton does not have an adequate nutrient source (Valdes et al., 2017).

A positive correlation is also observed between the cladoceran Pleopis polyphemoides, the chaetognath Parasagitta setosa and ammonium $\left(\mathrm{NH}_{4}\right)$, due to zooplankton's metabolism , that excretes this compound. Cyclops was negatively correlated with salinity, and Acartia clausi was negatively correlated with nitrate $\left(\mathrm{NO}_{3}\right)$ (Fig. 9).

In coastal waters, there was a positive correlation of Noctiluca scintillans density with salinity (Fig. 10). Very high abundances occur at salinities between 22-33 \%o and sometimes 10-15\% (Kopuz et al., 2014). The blooms generated by $N$. scintillans are closely related to food availability, especially to the presence of diatoms, which it consumes, controlling the dynamics of this phytoplankton group.

Phospahte $\left(\mathrm{PO}_{4}\right)$ correlated positively with meroplankton (Polychaeta, Balanus) and with the cladoceran Pleopis polyphemoides (Fig. 10). The explanation lies in the metabolic specificity of zooplankton which excretes a large fraction of phosphorus compounds (Pomeroy et al., 1963).

Positive correlations of copepods with nitrite $\left(\mathrm{NO}_{2}\right)$ and nitrate $\left(\mathrm{NO}_{3}\right)$ are also observed, copepods being generally known as ammonium-excreting microorganisms (Le Borgne et al., 1986). Oikopleura dioica has positively correlated with nitrite $\left(\mathrm{NO}_{2}\right)$, which might lead to a significant increase and acceleration of the export of carbon and other associated elements (Touratier et al., 2003).

In marine waters, a positive correlation of the copepod Calanus euxinus with nitrate $\left(\mathrm{NO}_{3}\right)$ is observed. The copepod Paracalanus parvus parvus was correlated with salinity, and the dinoflagellate N.scintillans with phosphate $\left(\mathrm{PO}_{4}\right)$ (Fig. 11), this microorganism accumulating and regenerating large amounts of dissolved inorganic nutrients and more complex organic substances (Zhang et al ., 2017). Cladoceran Evadne spinifera, a thermophilic and stenohaline species, recorded a positive correlation with salinity (Fig. 11). 


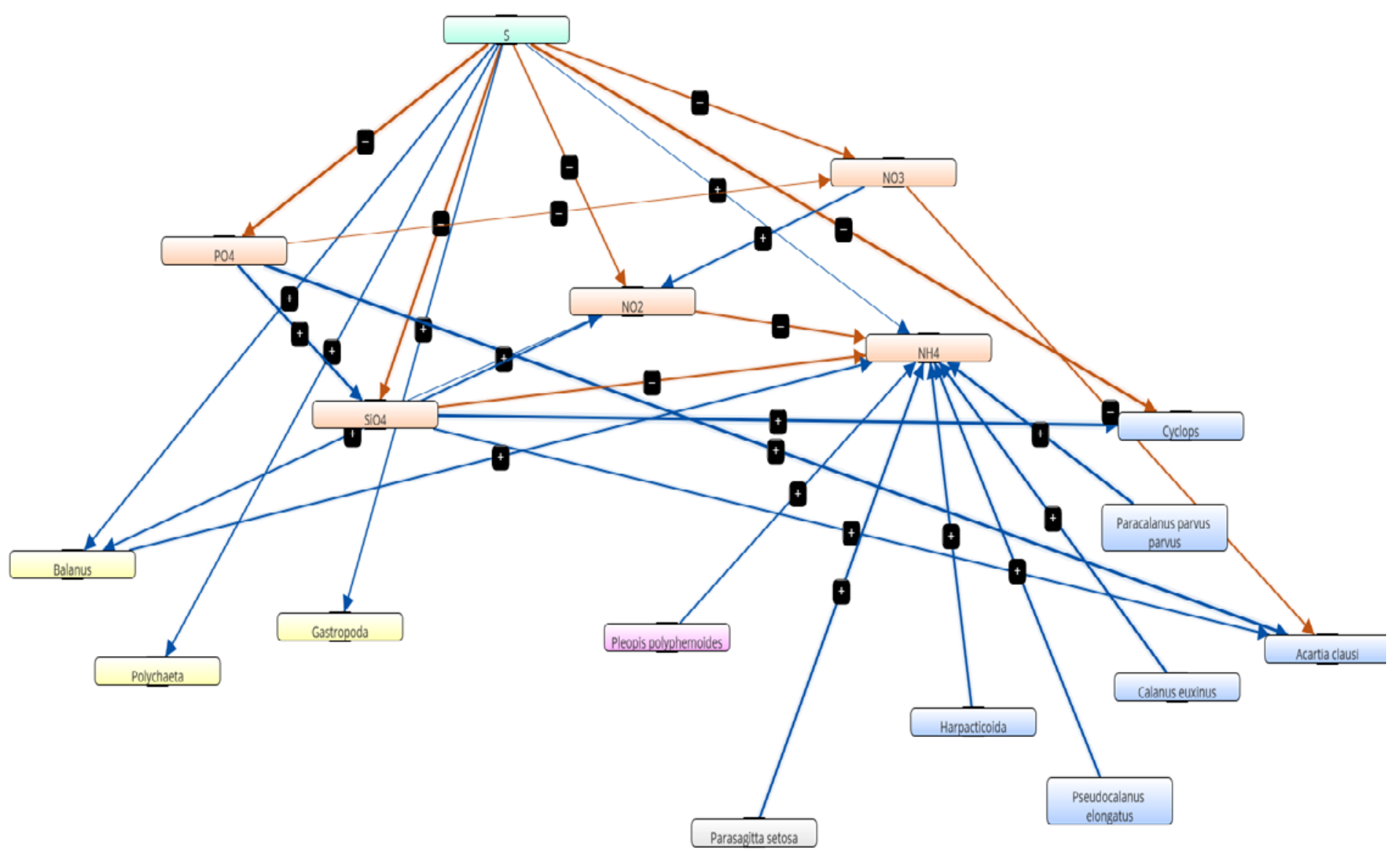

Fig. 9. Fuzzy Cognitive Map - connections between physicochemical parameters and mesozooplankton species in waters with variable salinity- Romanian Black Sea, 2008-2018 


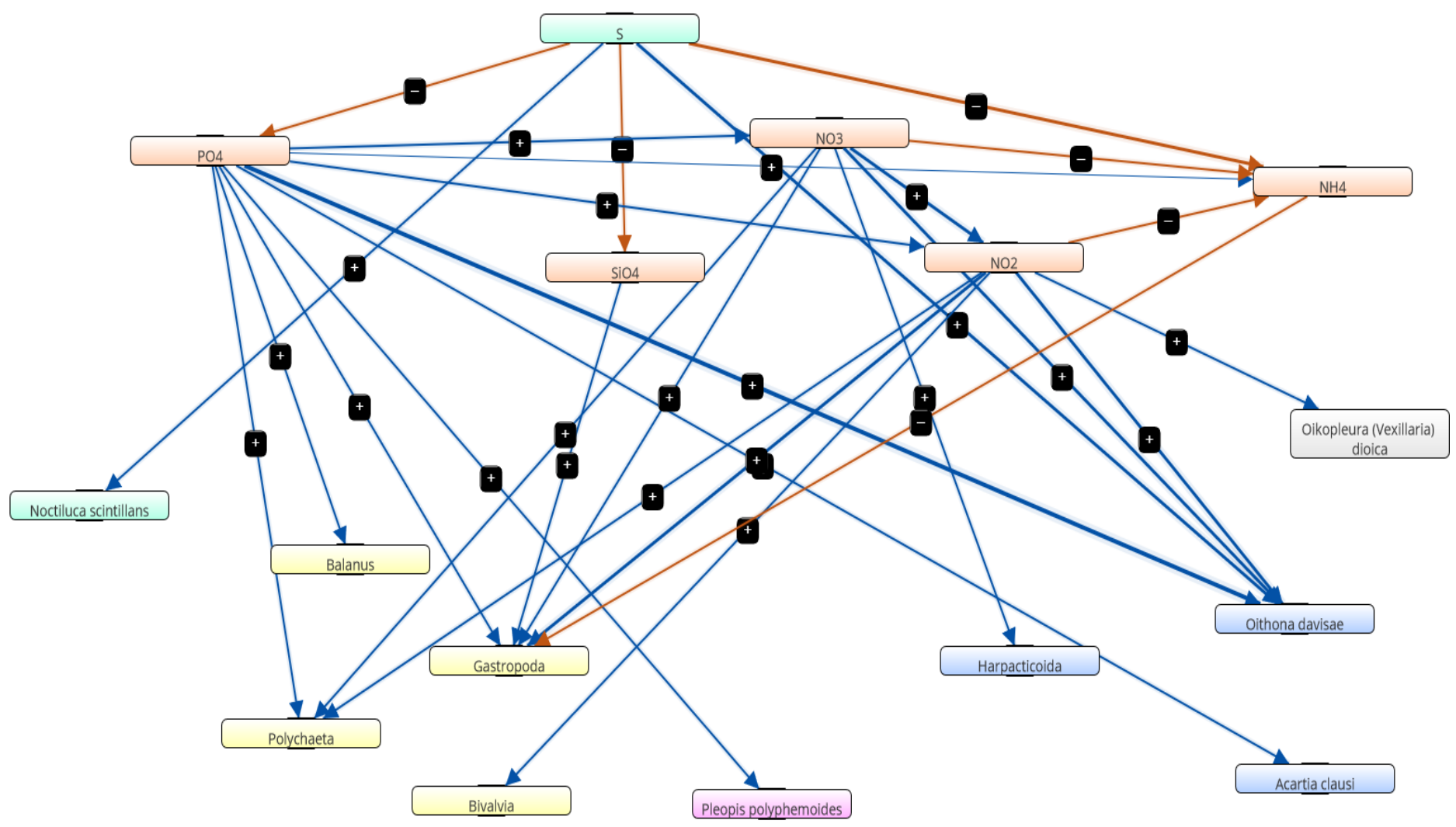

Fig. 10. Fuzzy Cognitive Map - connections between physicochemical parameters and mesozooplankton species in coastal waters- Romanian Black Sea, 2008-2018 


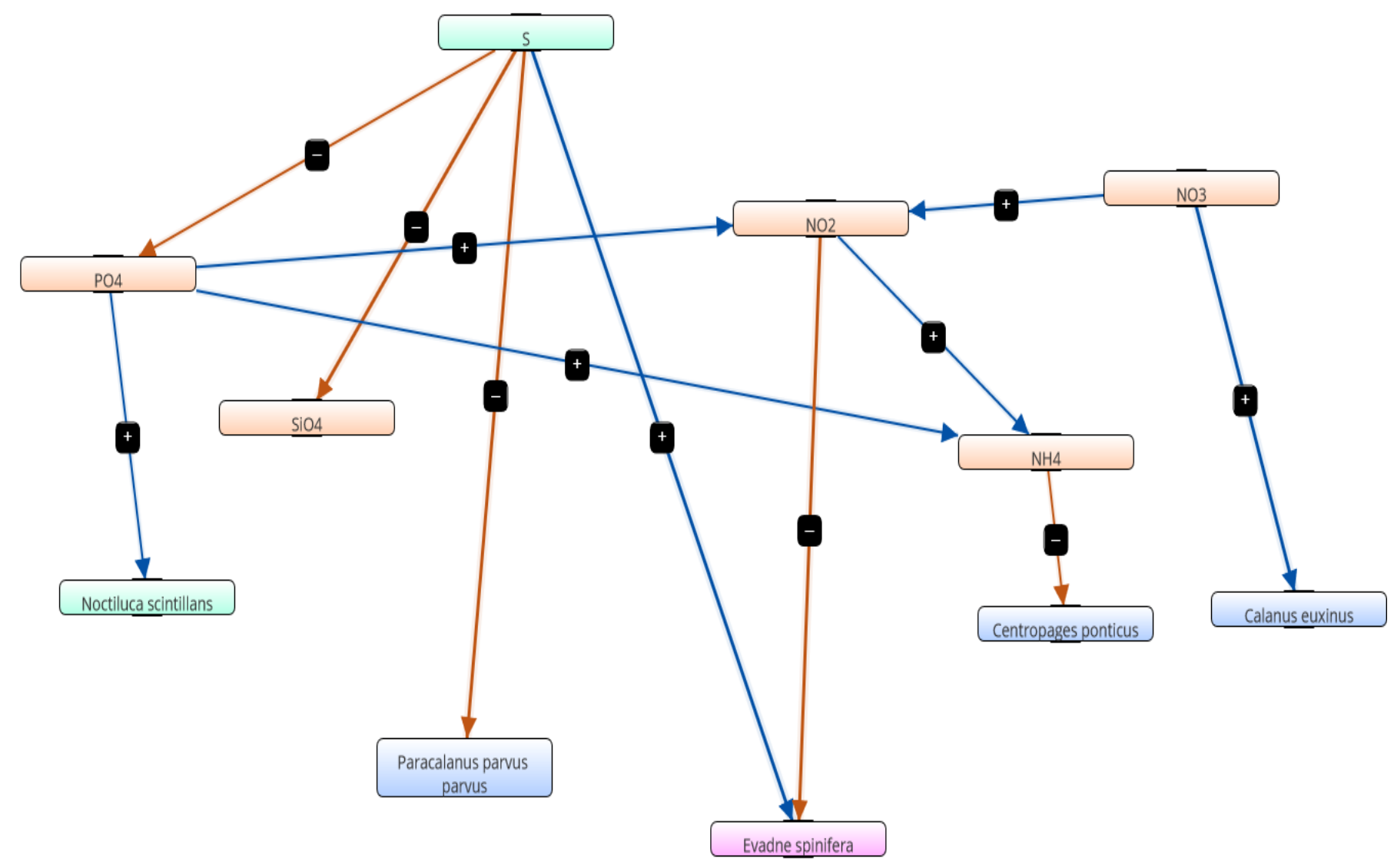

Fig. 11. Fuzzy Cognitive Map - connections between physicochemical parameters and mesozooplankton species in marine waters- Romanian Black Sea, 2008-2018 
To test possible changes in the marine ecosystem, we used the Mental Modeler software, which assigns hypothetical values to environmental factors (from - 1 to +1 ), generating scenarios that can occur in the marine ecosystem, in the conditions of climate change expressed as salinity and nutrients changes.

Zooplankton plays an important role in shaping the extent and pace of climate change, much of the $\mathrm{CO}_{2}$ that is fixed by phytoplankton is eaten by zooplankton and eventually sinks to the seabed. Much of this carbon can be locked up in sediments and removed from the carbon cycle. Zooplankton also facilitates this process by moving large quantities of carbon from the water's surface to deeper layers when they dive each day into the depths to avoid nearsurface predatory fish (Richardson, 2008).

Considering a dry season scenario which is presumably alternating with high precipitation as one of the climate change consequences, in waters with variable salinity, at an 50\% salinity increasing, there is an increase in the density of copepods Cyclops and Acartia clausi, and a significant decrease of meroplanktonic elements, mainly Gastropoda densities (Fig. 12).

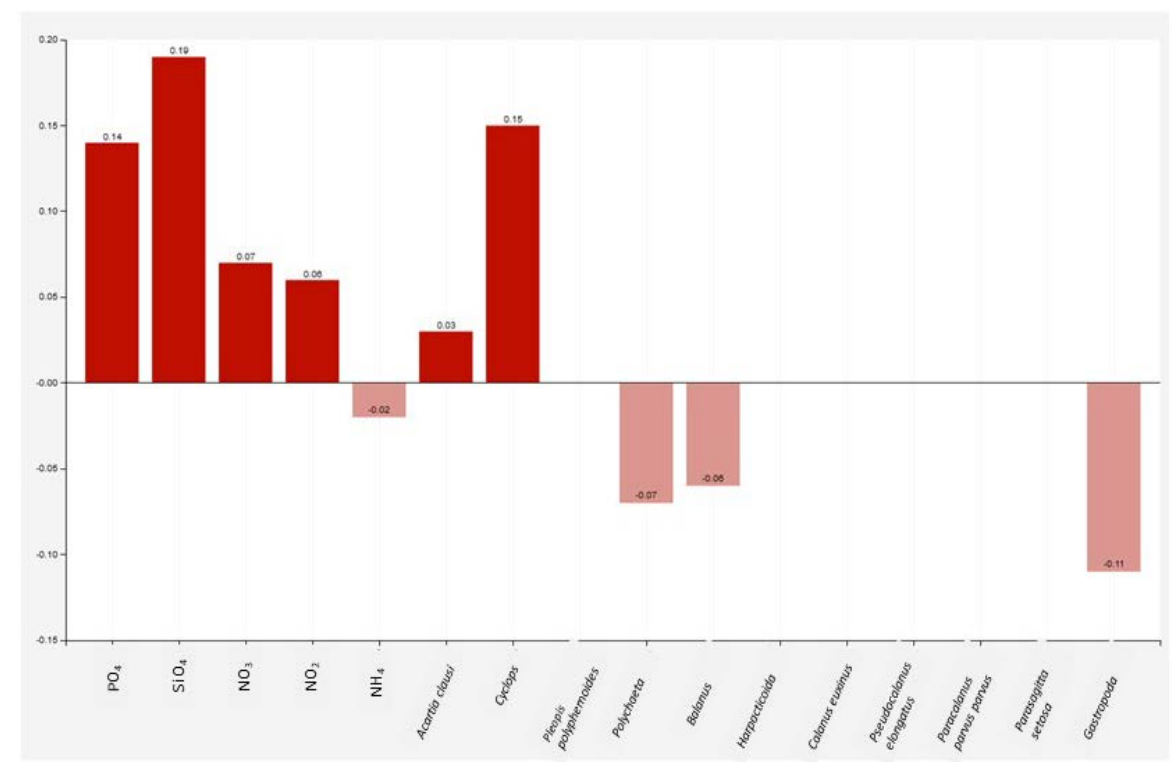

Fig. 12. Response of mesozooplankton species to possible changes in environmental conditions (salinity) - waters with variable salinity Romanian Black Sea, 2008-2018

In coastal waters, a $27 \%$ decreasing of phosphate concentration would lead to a significant decrease in the quantitative composition of mesozooplankton, the copepod Oithona davisae being the most affected in these conditions (Fig. 13). 


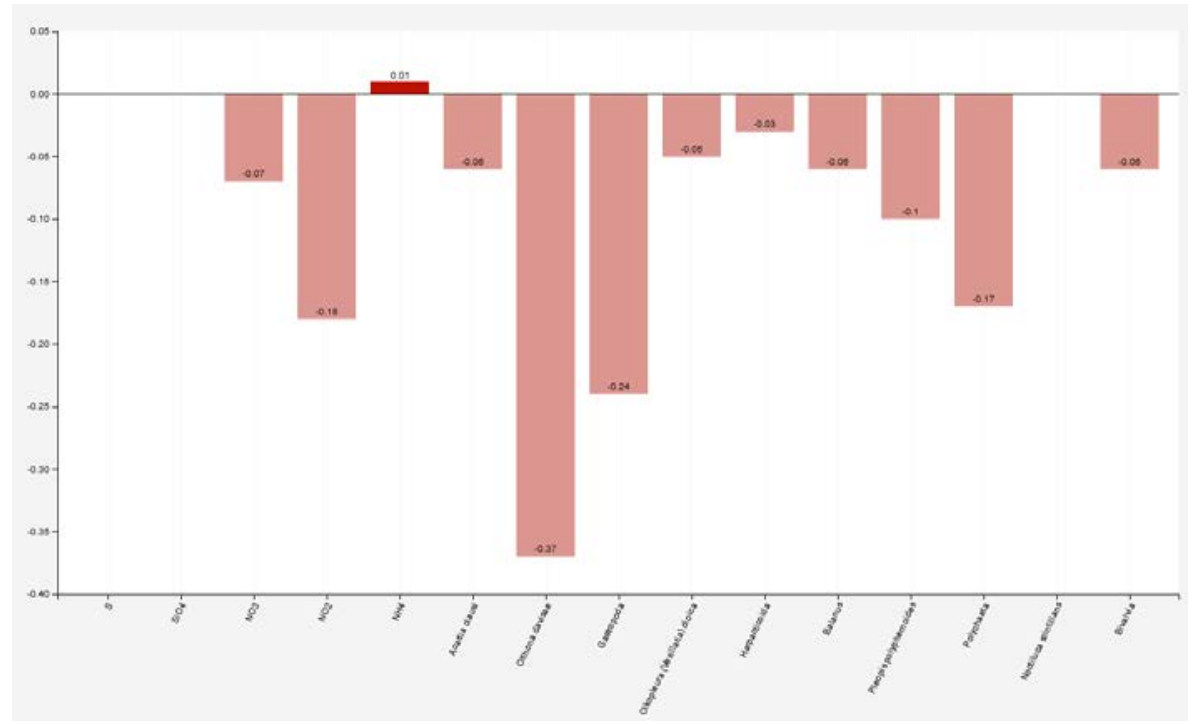

Fig. 13. Response of mesozooplankton species to possible changes in environmental conditions $\left(\mathrm{PO}_{4}\right)$ - coastal waters

In marine waters, an extreme condition of $100 \%$ salinity rise would have a negative influence on copepods, generating decreases in their density. At the same time, Evadne spinifera showed a quantitatively increase (Fig. 14).

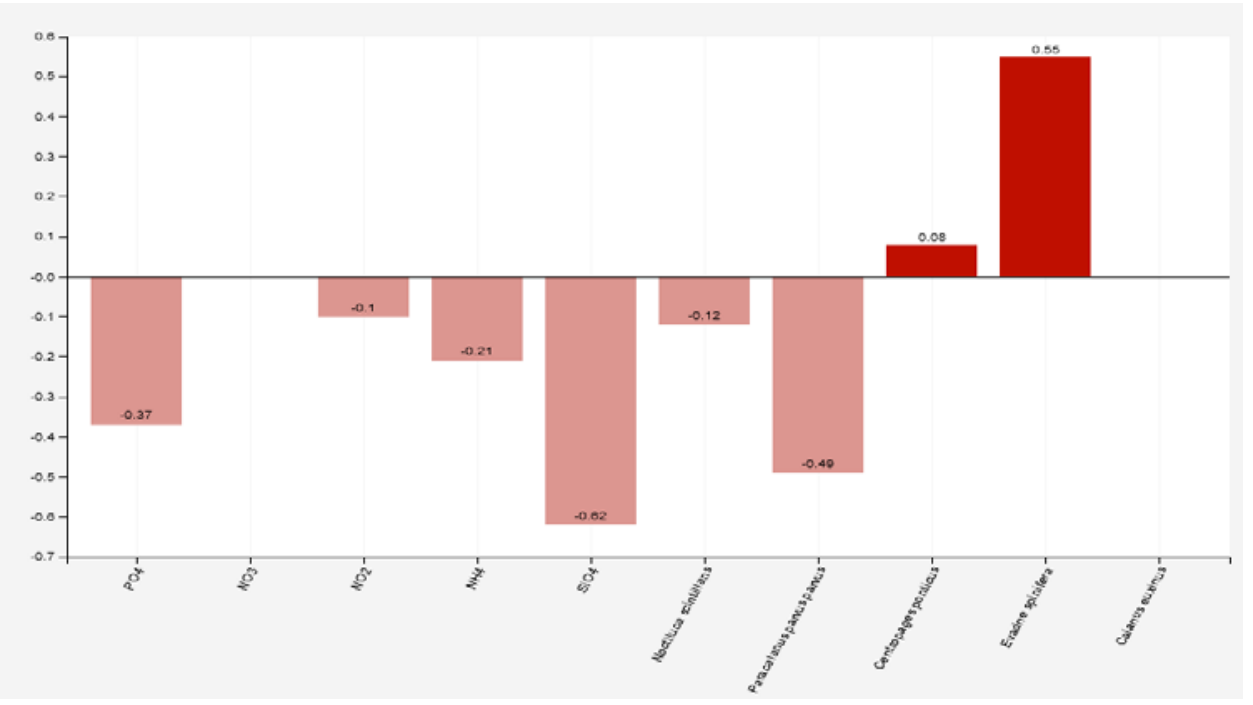

Fig. 14. Response of mesozooplankton species to possible changes in environmental conditions (salinity) - marine waters-

Romanian Black Sea, 2008-2018 


\section{CONCLUSIONS}

From the 32 identified mesozooplanktonic species, Copepoda was best represented along the Romanian Black Sea, reaching the highest number. Species of Cladocera were better represented in waters with variable salinity, under the Danube's influence, while in marine waters the meroplanktonic component showed a better development.

The quantitative structure of the mesozooplankton's community showed variations. The variable salinity and coastal waters were characterized by the dominance of the fodder component, while in marine waters, the nonfodder one was better represented. The fodder component was represented in coastal and marine waters by Cladocera and Copepoda mainly, these groups recording the highest average densities.Similarities of $60 \%$ and $80 \%$ were recorded between the analyzed stations, given by the average density values, both for the fodder and for the nonfodder component.

The main physicochemical parameters that showed significant correlations with the mesozooplanktonic species were $\mathrm{S}$ (salinity), $\mathrm{NO}_{2}{ }^{-}$ (nitrite), $\mathrm{NO}_{3}{ }^{-}$(nitrate), $\mathrm{PO}_{4}{ }^{3-}$ (phosphate) and $\mathrm{NH}_{4}{ }^{+}$(ammonium) The semiquantitative models used significant correlation coefficients between physicochemical parameters and mesozooplankton species abundance, depending on the water body. There was a variation in the number of mesozooplankton species along the salinity gradient, which showed significant correlations, nine species showing positive correlations in waters with variable salinity, in coastal waters ten species, and in marine waters only five species.

In waters with variable salinity, the fuzzy cognitive map showed positive correlations between the meroplankton component and salinity, this parameter influencing the larvae's survival rate. Positive correlation was also recorded between species of Copepoda and ammonium $\left(\mathrm{NH}_{4}\right)$, driven by the copepod's excretion.

In coastal waters, copepods showed again a positive correlation with nitrates and nitrites. Another positive correlation was between Noctiluca scintillans and salinity and between Oikopleura dioica and nitrite $\left(\mathrm{NO}_{2}\right)$.

In marine waters, copepods were positively correlated with nitrate $\left(\mathrm{NO}_{3}\right)$ and salinity, $N$. scintillans with phosphate $\left(\mathrm{PO}_{4}\right)$ and Evadne spinifera with salinity.

The tested scenarios that can occur in the marine ecosystem, in the context of climate change revealed significant changes in species abundances due to salinity and nutrients regime.

To reveal the roles of zooplankton in the marine ecosystem dynamics, studies of zooplankton should be carried out by integrating physical, biological, and fisheries scientific disciplines, to the extent possible. 
Acknowledgement. This study has been carried out with financial support from the NUCLEU INTELMAR Programme, funded by the Romanian Ministry of Education, Research and Digitization, project no. PN19260202 "Ecological, ecophysiological and biotechnological research in Romanian marine ecosystems”.

\section{REFERENCES}

Abdel-Aziz N. M., Gharib S.M., Dorgham M.M. (2006), The interaction between phytoplankton and zooplankton in a Lake-Sea connection, Alexandria, Egypt. International Journal of Oceans and Oceanography, 1(1): 151-165. https://www.ripublication.com/ijaer.htm

Aknaf A., Akodad M., Moume, A., Ben Chekroun K., Elhamouti C., Bailal A., Baghour, M. (2017), Study of the Spatial and Temporal Variation of Physical-Chemical Parameters Characterizing the Quality of Surface Waters of the Lagoon Marchica- North-East Morocco. Journal of Materials and Environmental Sciences, 8:3216-3225.

Alexandrov B., Arashkevich E., Gubanova A., Korshenko A. (2014), Manual for mesozooplankton sampling and analysis in the Black Sea monitoring (Black Sea Commission), 41p.

Anger K. (2003), Salinity as a key parameter in the larval biology of decapod crustaceans, Invertebrate Reproduction \& Development, 43:29-45. doi.10.1080/07924259.2003.9652520

Atienza, D., Saiz, E., Calbe, A. (2006), Feeding ecology of the marine cladoceran Penilia avirostris: natural diet, prey selectivity and daily ration, Marine Ecology Press Series, 315:211-220. doi:10.3354/meps315211

Bentley, K.M.; Pierson, J.J.; Glibert, P.M.(2021), Physiological Responses of the Copepods Acartia tonsa and Eurytemora carolleeae to Changes in the Nitrogen:Phosphorus Quality of Their Food. Nitrogen, 2:62-85. https://doi.org/10.3390/nitrogen2010005

Boicenco L., Abaza V., Anton E., Bișinicu E,. Buga L., Coatu V., Damir N., Diaconeasa D., Dumitrache C., Filimon A., Galațchi M., Golumbeanu M., Harcotă G., Lazăr L., Marin O., Mateescu R., Maximov V., Mihailov E., Nenciu M., Nicolaev S., Niţă V., Oros A., Pantea E., Radu G., Spinu A., Stoica E., Tabarcea C., Timofte F, Țiganov G., Țoțoiu A, Vlas O., Vlăsceanu E., Zaharia T., (2018), Study on the elaboration of the report regarding the ecological status of the Black Sea marine ecosystem according to the requirements of Art. 17 - Strategy Framework Directive for the Marine Environment (2008/56/EC), 331p. (in Romanian). 
Caroppo C., Buttino I., Camatti E., Caruso G., De Angelis R., Facca C., Giovannardi F., Lazzara L., Mangoni O., Magaletti E. (2013), State of the Art and Perspectives on the Use of Planktonic Communities as Indicators of Environmental Status in Relation to the EU Marine Strategy Framework Directive, Biol. Mar. Mediterr, 20(1):65-73. doi:10.1093/icesjms/fsw101

Clarke K.R., Gorley R.N., Somerfield P.J., Warwick R.M. (2014), Change in marine 21 communities: an approach to statistical analysis and interpretation, 3rd edition. PRIMER-22 E: Plymouth.

Grasshoff K., Kremling, K., Ehrhardt M. (1999), Methods of Seawater Analysis. Third, com. Wiley-VCH Verlag GmbH, 666 p.

Gray S, Cox L., Henly-Shepard S. (2013), Mental modeler: A fuzzy-logic cognitive mapping modeling tool for adaptive environmental management. Proceedings of the 46th International Conference on Complex Systems: 963-973. doi: 10.1109/HICSS.2013.399

Harris R. P., Wiebe P. H., Lenz J., Skjoldal H. R., Huntley M. (2000), Zooplankton Methodolgy Manual, Academic Press, 684 p.

Ismail A.H., Adnan A., A., M. (2016), Zooplankton Composition and Abundance as Indicators of Eutrophication in Two Small Man-made Lakes, Trop Life Sci Res: 27(1): 31-38. doi: 10.21315/tlsr2016.27.3.5

Jurczak T., Frankiewicz A.W., Frankiewicz, P., Kaczkowski Z., Oleksińska Z., Bednarek A, Zalewski M. (2019), Comprehensive approach to restoring urban recreational reservoirs. - Use of zooplankton as indicators for the ecological quality assessment. Science of the Total Environment, 653:1623-1640. doi :10.1016/j.scitotenv.2018.08.006

Kennish, M. J. (2000). Practical Handbook of Estuarine and Marine Pollution. CRC Press.https://doi.org/10.1201/9781420038484

Kopuz U., Feyzioglu A.M., Valente A. (2014), An unusual red-tide event of Noctiluca scintillans (Macartney) in the southeastern Black Sea. Turk. J. Fish. Aquat. Sci:, 14:261-268. doi: 10.4194/1303-2712-v14_1_28

Pestorić B., Lučić D., Joksimović D. (2010), Cladocerans spatial and temporal distribution in the Coastal South Adriatic waters (Montenegro). Studia marina, 25(1): 101-120.

Pomeroy L. R., Matthews H. M., Min H. S. (1963), Excretion of phosphate and soluble organic phosphorus compounds by zooplankton. Limnology and Oceanography: 8:50-55. doi.10.4319/lo.1963.8.1.0050

Richardson A. J. (2008), In hot water: zooplankton and climate change, ICES Journal of Marine Science, 65: 279-295. doi.10.1093/icesjms/fsn028

Romin M. , Azad S., Saleh E. (2021), Variations in the Physicochemical Water Parameters and Phytoplankton Community in Coastal Water of Kudat, Sabah, Malaysia. Journal of Geoscience and Environment Protection, 9:86-99. doi: 10.4236/gep.2021.97006 
Touratier F, Carlotti F, Gorsky G. (2003), Individual growth model for the appendicularian Oikopleura dioica . Marine Ecology Progress Series:, 248: 141-163. doi: $10.3354 /$ meps248141

Valdés V., Fernandez C., Molina V., Escribano R. (2017), Nitrogen excretion by copepods and its effect on ammonia-oxidizing communities from a coastal upwelling zone. Limnology and Oceanography: 63(1):278-294. doi.10.1002/lno.10629

Zhang S., Liu H., Glibert P.M., Guo C., Ke Y. (2017), Effects of prey of different nutrient quality on elemental nutrient budgets in Noctiluca scintillans. Sci Rep: 7:7622. doi: 10.1038/s41598-017-05991-w 


\section{List of identified species}

\begin{tabular}{|c|c|c|c|}
\hline \multirow[t]{2}{*}{ Class and species } & \multicolumn{3}{|c|}{ Water body } \\
\hline & Variable salinity & Coastal & Marine \\
\hline \multicolumn{4}{|l|}{ Appendicularia } \\
\hline Oikopleura (Vexillaria) dioica (Fol, 1872) & * & $*$ & $*$ \\
\hline \multicolumn{4}{|l|}{ Bivalvia } \\
\hline Bivalvia (Linnaeus, 1758) & $*$ & $*$ & $*$ \\
\hline \multicolumn{4}{|l|}{ Branchiopoda } \\
\hline $\begin{array}{l}\text { Bosmina (Bosmina) longirostris (O.F. } \\
\text { Müller, 1785) }\end{array}$ & $*$ & $*$ & \\
\hline Chydorus sphaericus (O.F. Müller, 1776) & * & & \\
\hline Daphnia (O.F. Müller, 1785) & $*$ & & \\
\hline Daphnia cucullata (G.O. Sars, 1862) & $*$ & & \\
\hline Daphnia longispina (O.F. Müller, 1776) & $*$ & & \\
\hline Evadne spinifera (P.E.Müller, 1867) & $*$ & $*$ & $*$ \\
\hline Moina (Baird, 1850) & $*$ & & \\
\hline Penilia avirostris (Dana, 1849) & $*$ & $*$ & $*$ \\
\hline Pleopis polyphemoides (Leuckart, 1859) & $*$ & $*$ & $*$ \\
\hline Pseudevadne tergestina (Claus, 1877) & $*$ & $*$ & $*$ \\
\hline \multicolumn{4}{|l|}{ Dinophyceae } \\
\hline $\begin{array}{l}\text { Noctiluca scintillans (Macartney Kofoid \& } \\
\text { Swezy, 1921) }\end{array}$ & $*$ & $*$ & * \\
\hline \multicolumn{4}{|l|}{ Gastropoda } \\
\hline Gastropoda (Cuvier, 1795) & $*$ & $*$ & $*$ \\
\hline \multicolumn{4}{|l|}{ Hexanauplia } \\
\hline $\begin{array}{l}\text { Acartia (Acartiura) clausi (Giesbrecht, } \\
\text { 1889) }\end{array}$ & $*$ & $*$ & $*$ \\
\hline Balanus (Costa, 1778) & $*$ & $*$ & $*$ \\
\hline Calanus euxinus (Hulsemann, 1991) & $*$ & $*$ & $*$ \\
\hline Centropages ponticus (Karavaev, 1895) & $*$ & $*$ & $*$ \\
\hline Cyclops (Müller O.F., 1785) & $*$ & $*$ & $*$ \\
\hline Eurytemora affinis affinis (Poppe, 1880) & $*$ & & $*$ \\
\hline Harpacticoida (Sars M., 1903) & $*$ & $*$ & $*$ \\
\hline $\begin{array}{l}\text { Oithona brevicornis brevicornis } \\
\text { (Giesbrecht, 1891) }\end{array}$ & $*$ & $*$ & $*$ \\
\hline $\begin{array}{l}\text { Oithona davisae (Ferrari F.D. \& Orsi, } \\
\text { 1984) }\end{array}$ & $*$ & $*$ & $*$ \\
\hline Oithona nana (Giesbrecht, 1893) & $*$ & $*$ & $*$ \\
\hline Oithona similis (Claus, 1866) & $*$ & $*$ & $*$ \\
\hline
\end{tabular}




\begin{tabular}{|l|c|c|c|}
\hline Paracalanus parvus parvus (Claus, 1863) & $*$ & $*$ & $*$ \\
\hline Pontella mediterranea (Claus, 1863) & & $*$ & $*$ \\
\hline Pseudocalanus elongatus (Boeck, 1865) & $*$ & $*$ & $*$ \\
\hline Malacostraca & & $*$ & $*$ \\
\hline Decapoda (Latreille, 1802) & $*$ & $*$ & \\
\hline $\begin{array}{l}\text { Mesopodopsis slabberi (Van Beneden, } \\
\text { 1861) }\end{array}$ & & $*$ & $*$ \\
\hline Polychaeta & $*$ & $*$ & $*$ \\
\hline Polychaeta (Grube, 1850) & & & \\
\hline Sagittoidea & & $*$ & \\
\hline Parasagitta setosa (J. Müller, 1847) & & & \\
\hline Phoronida & & & \\
\hline Phoronida (Hatschek, 1888) & & & \\
\hline
\end{tabular}

